$\ddot{\otimes}$ STFM SOCIETY OF TEACHERS OF From the Society of Teachers FAMILY MEDICINE of Family Medicine

Ann Fam Med 2020;18:87-88. https://doi.org/10.1370/afm.2511..

\section{BUILDING A DIVERSE ACADEMIC FAMILY MEDICINE WORKFORCE: URM INITIATIVE FOCUSES ON FOUR STRATEGIC AREAS}

As the US population becomes increasingly racially and ethnically diverse, it becomes more important than ever to increase the diversity of the family medicine workforce. Racial and ethnic minority groups experience significant health care disparities that result in unacceptable negative health outcomes. ${ }^{1,2}$ At the same time, the racial and ethnic demographics of our broader population are not reflected in our physician and faculty workforce.

Underrepresented in medicine (URM) is defined by the Association of American Medical Colleges as those racial and ethnic groups that are underrepresented in the medical profession relative to their number in the general population. ${ }^{3}$ While $33 \%$ of the US population are from URM groups, only $7.7 \%$ of academic full-time faculty are URM. ${ }^{4,5}$ The percentages of medical school graduates by race and ethnicity also don't reflect the broader population. Whites (58.8\%) and Asians (19.8\%) continue to represent the largest proportion of medical school graduates in 2015. By contrast, the 2015 medical school graduates comprise 5.7\% Black or African Americans and 4.6\% Hispanic or Latinos. ${ }^{5}$

To achieve health equity, it is critical to increase the diversity of family medicine faculty. URM faculty are more likely to engage in health disparities research and to educate their students and residents in racial and cultural competencies for underserved populations. ${ }^{6,7}$ URM faculty also provide critical mentorship and support for URM students and URM pipeline programs, directly contributing to efforts to increase the diversity of primary care physicians. ${ }^{8}$ The quality of medical care is enhanced by URM physicians, who are more likely to practice in underserved communities and who receive increased satisfaction and quality-ofcare ratings from their minority patients. ${ }^{6}$

In recognition of these factors and the need to overcome inequities, the Society of Teachers of Family Medicine (STFM) and the STFM Foundation has committed to a multi-year URM Initiative to increase the number of URM family medicine educators and promote health equity.

The STFM URM Initiative aims to:
- Increase the percentage of URM family medicine faculty

- Increase the number of solutions-focused, adaptable URM leaders within and across the health care system

Four work groups will develop and disseminate strategies and execute the objectives under the following four focus areas:

- Mentorship

o Create opportunities for developing meaningful relationships that lead to career advancement and leadership within STFM and academic medicine

o Develop mentors who have the skills to help URM students, residents, and faculty improve resiliency, satisfaction, and retention in academic family medicine

- Leadership

o Increase the percentage of URM family medicine faculty in leadership positions in academic medicine

o Raise awareness of the structural barriers to URM achievement

- URM Faculty Pipeline

o Increase the percentage of URM students and URM family medicine residents with an interest in teaching

o Increase the percentage of URM family medicine faculty

o Increase the percentage of URM community preceptors in family medicine teaching sites who receive resources to improve their teaching skills

- Scholarship

o Increase the percentage of URM students, residents, and faculty who have the skills to produce scholarly research

\section{Laying the Groundwork}

In 2018, the STFM Foundation launched an

"Underrepresented in Medicine" fundraising campaign to support URM faculty, URM community teachers, and URM medical students and residents going into academic family medicine. The funds raised have been used to support increased URM participation in existing STFM programs, to implement some new initiatives, and for outreach to outside organizations.

To date, the STFM Foundation has supported: a preconference workshop and multiple sessions within the 2019 STFM Annual Spring Conference on URM leadership development, scholarship, health equity, recruitment and retention, and holistic admissions; an URM Leadership series of STFM Blog Posts; a Writing Skills and Mentoring Fellowship for Minority Faculty; and scholarships for existing STFM programs for students, residents, new faculty, and emerging leaders. 


\section{A New Phase: The URM Oversight Committee \& Work Groups}

A new URM Oversight Committee was appointed in fall 2019 to provide strategic direction, monitor the progress of the work, and communicate with STFM members and the STFM Foundation about the work being done. The Oversight Committee will convene in February 2020 to develop strategies, budgets, timeframes, and measures to achieve the objectives within each focus area. The following members and STFM staff are serving on the committee:

Edgar Figueroa, MD, MPH, (Chair); David Acosta, $\mathrm{MD}_{i}$ Kathryn Fraser, PhD (Mentorship Work Group Leader); Cesar Gonzalez, PhD, LP, ABPP (Scholarship Work Group Leader); Mindy Householder, Byron Jasper, $\mathrm{MD}, \mathrm{MPH}_{i}$ Danielle Jones, $\mathrm{MPH}_{i}$ Leon McCrea, II, MD, MPH, Vince Munoz; Elizabeth Naumburg, MD (Leadership Work Group Leader); Mary Theobald, MBA; Maili Velez-Dalla Tor, MD, FAAFP (URM Faculty Pipeline Leader); Emily Walters; Judy Washington, $\mathrm{MD}$.

Each of the 4 focus areas has been tasked to a small work group, consisting of a team leader from the Oversight Committee, STFM members with an interest and expertise in the focus area, and staff.

The work of the Oversight Committee and all 4 work groups is anticipated to take place over the next 3 years, with plans to sustain the programs and resources that arise out of this phase in future years as part of STFM's Strategic Plan.

STFM is committed to promoting health equity and increasing the number of URM family medicine educators and leaders. Together, we can build a more diverse and inclusive workforce.

\section{Emily Walters}

\section{References}

1. Laviest TA, Gaskin D, Trujillo AJ. Segregated Spaces, Risky Places: The Effect of Racial Segregation on Health Inequalities. Washington, DC: Joint Center for Political and Economic Studies; 2011.

2. National Institutes of Health. National Institutes of Health Fact Sheet-Health Disparities https://archives.nih.gov/asites/ report/09-09-2019/report.nih.gov/nihfactsheets/ViewFactSheet2666. html?csid =124\&key=H\#H. Accessed Nov 22, 2019.

3. AAMC. The status of the new AAMC definition of "underrepresented in medicine" following the Supreme Court's decision in Grutter. 2004. https://services.aamc.org/AMCAS2_2010/WebApp/Help/ WebHelp/Disadvantaged_Status.htm. Accessed Nov 22, 2019.

4. Census.gov. Quick Facts United States. 2018. https://www.census. gov/quickfacts/fact/table/us. Accessed Sep 4, 2019.

5. Diversity of the Physician Workforce: Facts and Figures 2014. 2014; https://www.aamc.org/data-reports/workforce/report/diversity-factsfigures. Accessed Nov 22, 2019.

6. AAPCHO.org. Fact Sheet: The Need for Diversity in the Health Care Workforce. 2012. https://www.aapcho.org/wp/wp-content/ uploads/2012/11/NeedForDiversityHealthCareWorkforce.pdf. Accessed Sep 4, 2019.
7. Rodríguez JE, Campbell KM, Pololi LH. Addressing disparities in academic medicine: what of the minority tax? BMC Med Educ. 2015;15(1):6.

8. Mahoney MR, Wilson E, Odom KL, Flowers L, Adler SR. Minority faculty voices on diversity in academic medicine: perspectives from one school. Acad Med. 2008;83(8):781-786.

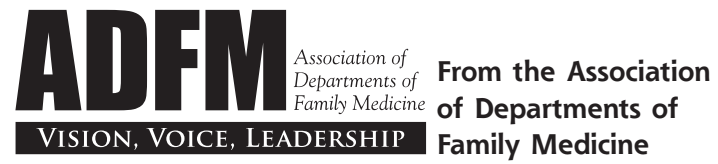

Ann Fam Med 2020;18:88-89. https://doi.org/10.1370/afm.2509.

\section{ADFM: FROM PAPER CLIPS TO PERFORMANCE-THE LAST 15 YEARS}

Patterns of organizational development appear more clearly in retrospect, as do their lessons learned. The Association of Departments of Family Medicine (ADFM) has evolved over more than 40 years in distinct phases as previously described by Borkan et al. ${ }^{1}$ This commentary aims to articulate major touchstones over the past 15 years, throughout the period of ADFM's first experience with an executive director and the evolution of "looking in" to "looking out."

\section{Strategic Focus}

ADFM first focused on becoming strategic around the turn of the century, having evolved from a "gripe and golf," inward-facing organization and annual conference to one that aimed to positively influence and foster growth in academic departments of family medicine. It was during this time that the decisions to bring on the first executive director and to start working through a committee structure were made. These steps were critical in advancing ADFM to a more activist rung on the organizational ladder. It took a few years of "finding our way" with leadership and the executive director to articulate a newly framed "vision, voice, leadership" with a completely revised logo and sense of purpose. A moment in time which directed us to become more outward and intentional along "our way" was in 2008 when a Board member observed that we need to get away from just "managing paper clips" to performing as an organization.

Flowing naturally from this moment, we pivoted to use our collective voice, and in 2012 to developing our first 3-year strategic plan. ${ }^{2,3}$ Importantly, ADFM's scope expanded to include issues in the whole of our discipline and in organized medicine-ranging from graduate medical education (GME) policy to care transformation. ADFM's strategic work continues to 